\title{
A YEAR OF THE EDUCATIONAL RESEARCH COMMITTEE
}

\author{
SAMUEL P. CAPEN
}

American Council of Education

The Educational Research Committee of the Commonwealth Fund held its first meeting approximately a year ago. Its members believe that the educational public will be interested in a brief report of the transactions of the Committee and of the educational research now going forward for which it stands sponsor.

In the summer of 1920 the Commonwealth Fund, at the suggestion of Professor Max Farrand of Yale University, then the Fund's General Director, appropriated $\$ 100,000$ for the purpose of encouraging educational research. It was understood that if satisfactory results were obtained from the expenditure of this amount during a single year, similar appropriations would be made annually for a period of five years. The policies to govern the expenditure of the appropriation were left to later determination.

The General Director organized a Conference of persons experienced in conducting or directing educational research, which met for three days in October, 1920, and recommended a plan of procedure to the Directors of the Commonwealth Fund. The plan proposed a departure from the current practice of philanthropic foundations in the conduct of educational research. Instead of setting up a more or less permanent agency with an expert personnel, it was recommended that the Commonwealth Fund subsidize individual investigators of proved capacity or of great promise to undertake limited researches. The Conference further indicated certain large fields in each of which numerous painstaking scientific studies are needed. These are: School revenues; the evaluation of school subjects and the determination of standards of accomplishment in them; reorganization of the administrative units of the public educational system; the establishment of standards and methods of supervision. The Conference also recommended that the Commonwealth Fund appoint a committee to consider and recommend projects for research and to assume executive responsibility for supervising the carrying on of such researches as might be subsidized by the Fund.

The Directors of the Commonwealth Fund accepted the Confer- 
ence's recommendations and appointed as the Educational Research Committee, Leonard P. Ayres, Samuel P. Capen, Lotus D. Coffman, Ellwood P. Cubberley, Charles H. Judd, Paul Monroe and Frank E. Spaulding. Professor Max Farrand, the General Director of the Fund, was designated to act as Chairman. Since the organization of the Committee Professor Spaulding has been obliged to resign and President James R. Angell has been appointed in his stead. During Professor Monroe's absence in the Orient, his place has been taken by Professor E. L. Thorndike. Professor Farrand has resigned as General Director of the Commonwealth Fund but remains as Chairman of the Educational Research Committee.

The Committee's general policy has followed closely the lines of the recommendations made by the Conference above referred to. During the year in which it has been in existence, a considerable number of requests for subventions have been presented to it. These have been exceedingly varied. Some of them have come from persons of no reputation as investigators and have been very vaguely defined. Some have been presented by distinguished scientists but called for the support of investigations which could hardly be classified as educational research. Certain requests have been made for the subsidization of special departments or of individuals in colleges or universities, without specification of the research projects to be supported by the subsidy. Other requests submitted by persons of known competence have sought subventions for projects carefully defined and budgeted. After a preliminary review of these heterogeneous askings, the Committee came to several conclusions which have since met with the approval of the Commonwealth Fund. In the first place, it decided to recommend no subventions to departments or individual workers in institutions for the carrying on of the regular research activities of such departments or individuals. Secondly, it determined to recommend the support of only those projects which were carefully defined both as to objectives and as to methods and which were accompanied by an itemized estimate of the cost of the undertaking. Thirdly, it decided for the present to recommend no subsidy for a longer period than one year. Within that time the investigation must either be terminated or a substantial report of progress submitted. Fourthly, the Committee recommended that wherever possible the Common wealth Fund should have its financial dealings with the institution or organized agency to which the investigator is attached, rather than with the individual. 
Since this last mentioned policy of the Committee has aroused considerable interest in various quarters, the form of contract which the Committee has devised is here quoted:

The institution will accept grants for educational researches from the Commonwealth Fund and will be responsible for their disbursement under the following agreements:

1. Salaries of officers who are relieved of regular duties to engage in researches are to be charged against the research grants at the rate of the salaries paid by the institution to such officers for regular teaching and administration, except in cases where explicit exceptions are arranged in advance.

2. The institution will disburse the grants under the following arrangements: On acceptance of the grant by the institution, the Commonwealth Fund shall deposit with the business officer of the institution a sum suitable to launch the Investigation and determined on the basis of the size of the grant; in the case of large grants this sum will amount in general to 20 or 30 per cent of the grant. When the initial sum is approaching exhaustion the business officer of the institution shall request a second deposit and shall render, as soon as possible, a full account of expenditures of the first deposit. In this manner there shall be successive deposits and successive accountings of the grant until the total amount has been used.

In disbursing the funds the institution will assume administrative responsibility for all payments of salaries. It will approve all appointments of assistants. It will make payments on the order of the investigator for supplies and equipment, and traveling expenses, and will render accounts on the latter items, showing the approval of the investigator.

At the termination of the grant it is understood that any unexpended balance shall revert to the Commonwealth Fuad, that final disposition of such supplies and equipment as are at hand is subject to the order of the Commonwealth Fund. If at the time of settlement property of any kind is left at the institution, it is understood that it becomes permanently a gift to the institution.

If the grant is made with specifications as to the amounts which are to be used for salaries, traveling expenses, and supples, the institution will limit all expenditures to the classes of items specified and will allow transfers from one class to another only on explicit permission of the administrative authorities of the institution, but it is understood that readjustments within a single class of expenditures may depart from the original terms of the budget.

3. The person responsible for the investigation will be required to fle a report on the investigation both with the administrative officers of the institution and with the Directors of the Commonwealth Fund at stated intervals.

It will be noted that the Commonwealth Fund does not propose to pay a bonus to persons who undertake educational research at its expense. The salaries paid investigators are to be the same as the salaries they would receive from the agencies which employ them. The Commonwealth Fund merely makes it possible for an investigator to carry on particular studies in which he is especially interested, and 
if necessary to be temporarily relieved of his regular institution al duties without pecuniary loss.

The Educational Research Committee has held three regular meetings. Two of these were devoted to the assignment among the most promising projects of the appropriation made for the academic year 1920-21. At the third meeting held in October, 1921, a portion of the appropriation for the academic year 1921-22 was assigned. A brief account of the projects which have been supported may be of interest. It will be noted that these all fall within the first three of the major fields of study indicated in the initial report of the Conference.

\section{Educational Finance}

The Commonwealth Fund has joined with three other educational foundations in appropriating to the American Council on Education a sum sufficient to carry forward a comprehensive investigation of educational finance in the United States. The program for public education laid down in legislative enactments and state constitutions will be examined to determine to what extent communities are already meeting the public desires. Effort will be made to investigate the cost of the program designated by the public. The possibility of effecting economies will be studied. The relation of educational expenditures to expenditures for other governmental purposes will be worked out. Intensive studies will be made in individual states that may be regarded as typical and the most important facts covering the country as a whole will be assembled and collated. The American Council on Education has appointed a special commission to take charge of this investigation.

An appropriation has also been granted to Columbia University for the preparation under the direction of Professor George D. Strayer of an initial report on city school budgets.

Measures and Standards of Achievement in School Subjects

Appropriations have been made to Columbia University for the conduct of two investigations under the direction of Professor E. L. Thorndike. The first investigation deals with the possible reorganization of the teaching material in Algebra and the methods of presenting that subject. What is known about the psychology of Algebra is to be collected, gaps in that knowledge are to be noted and filled by appro- 
priate investigations so far as possible, especially such as are important in possible changes in curricula and methods.

The second investigation relates to vocational guidance. It is designed to prepare standard tests of ability to continue school work, of ability to learn to do clerical work, and of ability in the mechanical trades and factory work. These tests are to be for use with boys and girls of approximately fifteen or sixteen years of age. It is expected that they will be so formulated as not to require the services of a psychologist to give them.

Two appropriations have been made to the University of Chicago, one for the use of Professor Judd and assistants in conducting a laboratory study of reading, and the other to Professor Morrison for devising a series of tests designed to measure the progress of pupils in French under ordinary high school instruction. In the investigation of reading, laboratory methods are used which teachers cannot employ. The movements of the eyes of adults and children are photographed under different conditions while they are reading various kinds of passages. It is expected that in this way the processes involved in good and bad reading and in mature and immature reading may be determined. Once the characteristics of various kinds of readings are ascertained it is possible to turn over to teachers many useful suggestions about the handling of pupils.

The French investigation is designed to throw light upon the effectiveness of grammatical as compared with non-grammatical methods in learning to read the foreign language; the pupil's command of grammatical usage in functional form compared with his knowledge of grammatical principles abstractly stated; and the relation between the ability to get the meaning of a series of French words stated apart from any context and the ability to react to the meanings of the same words when they are included in a piece of discourse.

An appropriation was made to be spent by the Chairman of the Educational Research Committee on a preliminary conference on the social studies. The conference outlined the problems in the reorganization of teaching material in the social studies and on the basis of its report the Committee has recommended further appropriations for a historical review of the social studies and an evaluation of current experiments in new methods of presenting these subjects.

An appropriation has been made to the Board of Education of Winnetka, Illinois, for the conduct of a study under the direction of Superintendent Carleton W. Washburne of periodical and reference 
literature to determine the commonly known and referred to historical and geographical material, with a view to the possible reorganization of the school material for teaching these subjects.

A grant has been made to Leland Stanford Junior University for a study, under the direction of Professor L. M. Terman, of gifted children in California. At present such children remain unidentified and submerged in the school's masses. The usual curriculum methods leave their intellectual and volitional resources largely undeveloped, sometimes possibly perverted. It may be more important to discover and to give appropriate educational opportunity to a single gifted child than to prevent the birth of a thousand feeble-minded. The investigation proposes to secure certain basic facts with reference to approximately one thousand school children of exceptionally superior intellectual ability, and to follow up the records and achievements of those pupils over a period of years.

A subsidy has been granted to the New York Association of Consulting Psychologists for a study partly similar in its objects to that of Professor Terman's. It is proposed to give intensive psychological examinations to students in a group of public schools in New York in order to determine the ability of children as they enter school, classify them as to ability and follow them up by re-examinations and through the services of a home worker, and thus to lay the basis of possible modifications of courses of study for the benefit of intellectually superior children, and that the less able children may be given better opportunities for development.

\section{Reorganization of the Administrative Units of the Puble Educational System}

The Fund has made a grant to the University of Minnesota to be under the direction of Professor L. V. Koos in studying and critically evaluating the present status of the junior college movement. There are now upwards of 300 of these institutions and they are multiplying rapidly. It is the purpose of the study to show their relations to secondary education, to the prevailing four year college of liberal arts, and to professional education. Such a study it is believed should have large influence in determining the trend of future efforts toward educational reorganization at the level of the lower years of the college course.

The Educational Research Committee believes that there should be 
many more appeals for subventions than have thus far come to it and that requests should be made by a much wider range of institutions. Indeed the conditions of the grant and the policy of the Committee are so flexible that any first-class project which can be clearly defined and budgeted is likely to receive favorable consideration. The Committee meets three times a year, in the fall, in the early spring, and in the early summer. The next meeting will be held March 4, 1922. Projects to receive consideration must be in the hands of the undersigned at least two weeks before the meeting of the Committee. 